\title{
Conferencia de prensa del 2 de enero de 2020. Presentación de la defensa legal de E. Raúl Zaffaroni y Raúl Gustavo Ferreyra a Evo Morales ${ }^{1}$
}

Revista Derechos en Acción ISSN 2525-1678/ e-ISSN 2525-1686 Año 5/No 14, Verano 2019-2020 (21 diciembre a 20 marzo), 997-1004 DOl: https://doi.org/10.24215/25251678e386

\section{Presidente Evo Morales:}

Después de ser presidente, nunca van a encontrar que soy corrupto. Quiero decirles, estimados y admirados abogados -penalista y constitucionalista-, que no van a encontrar algo así. Las acusaciones siempre vendrán así, por sedición. En este momento, decir "fuera al golpismo" ya es ser sedicioso. Es como si estuviera coartada la libertad de expresión. El que protesta contra el gobierno de facto ya es sedicioso. Evidentemente, allá las nuevas generaciones están con mucho miedo. Aún nos estamos recuperando, poco a poco. Los primeros días ni se imaginan. También se les calló a los medios de comunicación, con amenaza a la prensa nacional e internacional, que serían investigados con procesos de sedición si algún medio de comunicación protestaba contra el gobierno de facto. Esa es nuestra situación.

Por eso los saludo y estoy muy contento de estar con grandes profesionales, grandes defensores de los derechos. Nosotros estaremos siempre con la verdad y con la justicia. Evidentemente, queremos contar con esta clase de personalidades

\footnotetext{
1 El evento se desarrolló en el Hotel Bauen, Ciudad de Buenos Aires. El texto fue desgrabado por la abogada Cecilia Urquieta. La corrección se encontró a cargo de Pablo Germán Ali.
} 
muy conocidas. De verdad, para mí es un honor y un orgullo estar junto a ustedes, que me ayuden a defender y que sean nuestros defensores legales, no solamente para mí, sino sobre todo en la defensa ante la injusticia, la defensa de los pueblos humildes. Ustedes saben que en nuestro proceso de cambio siempre hemos defendido a los humildes de toda Bolivia. De verdad, estoy muy contento. Muchas gracias por ese apoyo, por esta defensa a nuestro movimiento.

\section{Dr. Raúl Gustavo Ferreyra:}

Muy buenos días a todos y todas. Es un doble honor que el Presidente nos haya postulado para asumir la asesoría y, eventualmente, la defensa jurídica ante los estrados y tribunales y, luego, llevar a cabo esta tarea de codefensor junto con el profesor Zaffaroni.

El primer señalamiento básico que quiero hacer es que Bolivia no es un Estado constitucional. Los Estados en el mundo se dividen en Estados constitucionales y no constitucionales. Bolivia está fuera del mundo: Bolivia es un Estado donde no existe la fuerza regulada racionalmente, Bolivia es un Estado de pura fuerza bruta. Los Estados constitucionales son Estados de Derecho, porque en ellos la fuerza se planea y realiza con determinada racionalidad, más o menos incompleta. O los Estados no constitucionales son Estados de "No Derecho", porque allí la fuerza carece de regulación y se administra, siempre, con una misión beligerante.

En segundo lugar, ignoramos si hasta este momento la autoridad de facto en Bolivia domina totalmente el aparato de la administración y el aparato del territorio; lo ignoramos porque no tenemos informaciones, de manera que nos atrevemos a decir que es un Estado de pura fuerza, aun en la hipótesis -queda flotando la duda- de si ejercen efectivamente el dominio del territorio.

En este mismo punto, quiero señalar que, en esta parte del mundo, nuestra América Latina deteriorada, colonizada y 
empobrecida, no existe actualmente un Estado de pura fuerza bruta como es el Estado boliviano en este momento. No hay nada similar, no podemos compararlo con nada, porque es el gobierno de la irracionalidad. En este sentido, la Asamblea boliviana todavía no ha aceptado ni rechazado la renuncia del presidente Evo Morales. En consecuencia, desde la comprensión del Derecho constitucional, nosotros estamos en presencia del presidente del Estado Plurinacional de Bolivia.

Juzgamos que es importantísima la atención de todos los latinoamericanos sobre esta cuestión, porque es un precedente nefasto y horrible, dado que nunca nos hemos enfrentado a una circunstancia de estas características. Deseo añadir, también, que la propia Constitución boliviana del 2009 ha dispuesto que todos los actos de quienes son usurpadores de poder o ejercen potestades que no le han sido asignadas son nulos de nulidad insalvable e insanable. Esto trae como directa consecuencia que todo lo que se hace en este momento en Bolivia es -como he señalado- fuerza completamente desregulada, sin ningún tipo de control y ningún tipo de garantía.

En cuanto nos concierne a nosotros estamos en presencia de un (des) orden de pura fuerza bruta, el Estado de Bolivia, que no es reconocido por la Argentina. En realidad, se trata de un verdadero desorden, razón por la cual la Argentina en ningún momento -entiendo- debería responder a ningún pedido que venga de Bolivia, pues no es un Estado constitucional. El hecho de que el presidente Morales esté hoy entre nosotros nos reconforta, como también nos reconforta que haya elegido la Argentina.

Casual o curiosamente, los argentinos y las argentinas tenemos un mandato muy específico desde 1853. Diría que contamos con una de las pocas constituciones en el mundo que no establece ninguna distinción entre nacionales y extranjeros; así que, presidente Evo Morales, acá somos todos exactamente iguales ante el Derecho, y no se puede tomar ninguna medida discriminatoria frente a un extranjero. Desde 1853 la Argentina equipara abiertamente a quienes han decidido vivir en este 
país, por la razón que fuera, por propia voluntad o porque han querido pedir asilo político, y a quienes hemos tenido la suerte -o la infelicidad- de nacer en este territorio.

Durante el mes de enero se suscitará una importantísima cuestión constitucional, porque termina el mandato del presidente, y termina también el mandato de los miembros de la Asamblea. En ese momento Bolivia entrará en una zona de acefalia absoluta, que no se encuentra resuelta por la Constitución. Por lo tanto, cualquier petición, en cualquier sentido, para extender o prorrogar los mandatos de las autoridades de facto, seguirá la línea brutal de esta fuerza bruta que estamos delineando.

Finalmente, debo decir entonces que, a nuestro juicio, en cuanto fenezcan los mandatos del presidente Evo Morales y de los miembros de la Asamblea, debería asumir la conducción de Bolivia, inmediatamente, la autoridad constitucional y regularmente constituida a ese momento y convocar de inmediato a elecciones. Ésta ha sido mi breve alocución y le voy a ceder la palabra al profesor Zaffaroni.

\section{Dr. Raúl Zaffaroni:}

Muy buenos días, señores y señoras. Realmente es muy poco lo que tendría que agregar a lo que acaba de decir el profesor Ferreyra. Es para mí un honor poder estar aquí, junto al presidente constitucional del Estado Plurinacional de Bolivia, y digo el "presidente constitucional" porque hasta el día 22 de enero es el presidente constitucional de Bolivia. Ustedes se preguntarán "por qué"; muchos dirán "renunció". Sí, renunció, pero la renuncia no ha sido tratada por el único órgano habilitado para aceptar o rechazar la renuncia, que es el Órgano Legislativo de Bolivia, es decir, la Asamblea Legislativa Plurinacional. La Asamblea no ha podido reunirse para tratar la renuncia, para aceptarla, para rechazarla, porque los diputados son gaseados, les tiran gases lacrimógenos, incluso para que no entren al recinto. La Asamblea no se ha reunido; en consecuencia, la situación es extrañísima. 
Si me preguntan, incluso, cuál es la situación jurídica del presidente Evo Morales, algunos podrían decir que tiene estatuto de refugiado o algo similar. Aclaro que esto no es correcto. Yo diría que tiene la inmunidad que le corresponde a un jefe de Estado extranjero, por lo menos hasta el 22 de enero tiene esa inmunidad. Esto es insólito. Mientras tanto, se titula presidente de Bolivia una señora que surge de un partido que tiene el 4,4\% de los votos.

Todos sabemos lo que ha pasado. Todos sabemos que hay por lo menos unos 38 muertos reconocidos, además de los heridos. Pero ha pasado algo peor, es decir, nuestra región ha tenido gobiernos de factos, hemos tenido violaciones de los derechos humanos, seguimos teniendo lamentablemente. Hay muchas situaciones conflictivas, es verdad, pero lo que dijo Ferreyra hace un momento es cierto: ninguna es como la de Bolivia, y ninguna es como la de Bolivia porque realmente se han salido del sistema planetario. En los últimos días hemos visto que el régimen o el ejercicio del poder boliviano -porque no sé si es un Estado realmente- ha violado normas elementales, las más elementales normas del Derecho de gentes que regulan la coexistencia entre Estados. Me refiero a hostigar embajadas, echar a representantes diplomáticos, violar la norma elemental del derecho de gentes de inmunidad de embajadas extranjeras.

Llamo la atención porque estamos tocando las normas más elementales que hay y que hacen a la coexistencia y a la comunidad jurídica mundial. Esto directamente -insisto- es salirse del sistema planetario, más allá del planteo del gobierno de facto, más allá de la violación a derechos humanos. Es una situación de fuerza -de fuerza bruta, decía Ferreyra-; es una situación de no derecho.

Muchas veces, cuando enseñamos derecho, a nosotros se nos ocurre inventar casos de laboratorio, y entonces se nos va la imaginación. Hemos inventado casos insólitos, situaciones insólitas, pero muchas veces nuestra creatividad docente es superada por la realidad, y éste es un caso en que la realidad 
supera todo lo que se nos pueda haber ocurrido. No encuentro otro caso históricamente dado, porque lo de Bolivia, al violar estas normas elementales, de la convivencia de la comunidad internacional, se convierte en un Estado, no ya de facto, sino en un Estado de no Derecho.

Aclaro que ante el Derecho argentino no se ha planteado ningún pedido de extradición. Lo único que hemos visto es una orden de detención, emanada de ningún juez, sino de dos fiscales, por el delito de sedición. La sedición es un delito objetivamente político, y por delito político no se puede solicitar la extradición de nadie, según establece el Tratado de extradición con Bolivia, que firmamos en el año 2014, y creo que lo firmó el Presidente Evo Morales también. Además, según las normas internacionales en materia de extradición, por delitos políticos no se extradita. El delito de sedición es objetivamente un delito político, es un delito contra los poderes políticos; el bien jurídico es el poder político. Pero insisto en que no hay pedido de extradición. Tampoco, según nos informa el colega Baltasar Garzón, hay ninguna gestión ante Interpol. De modo que, en ese sentido, aún no tenemos nada que hacer ante nuestros estrados argentinos ni Ferreyra ni yo. Cualquier cosa, estamos dispuestos a hacerlo si una eventualidad se llega a presentar, pero en este momento no hay absolutamente nada de esto.

¿Qué pasa el 23 de enero? Digo "23 de enero" porque serían las 00:00 horas del día siguiente 22. Hasta las 23:59, tenemos presidente constitucional y tenemos una Asamblea Legislativa Plurinacional. A partir de las 00:00 horas del 23, eso no existe más en Bolivia; se terminaron los mandatos. De alguna manera, hay que pensar cómo salir de esta situación que se ha creado, de este Estado de no Derecho. El mal está hecho, el daño está hecho. Ahora hay que pensar cómo se revierte. ¿Qué correspondería hacer en una situación de esta naturaleza? Bueno, es lo que decía el colega: ¿qué queda de autoridades constitucionales?, quedan los Tribunales, y por ende lo correcto sería lo que ya pasó alguna vez en la historia de Bolivia, es decir, que asuma la presidencia provisional el presidente del Tribunal Supremo, 
y de esa manera convoque a elecciones para que se normalice en lo posible esta situación.

Señoras, señores -insisto-, esto no tiene precedentes. Esto es muy grave para nuestras democracias, más allá de simpatías o antipatías. En nuestra región -no soy ingenuo- sabemos que hay serias dificultades, dificultades de toda índole. Las vamos a superar; los pueblos no se quedan quietos. Pero realmente esto rompe todas las reglas de convivencia internacional. Exageraron la nota, realmente. Tengamos mucho cuidado cuando en el mundo se tocan estos límites, cuidado con los límites mínimos del Derecho, mínimos de la convivencia entre Estados. En muchos órdenes, creo que la humanidad está tocando ciertos límites.

Hoy leía la noticia de un científico, para llamarlo de alguna manera, que experimentó con manipulación genética, fuera de protocolos. Cuidado con lo que estamos haciendo porque en cualquier orden donde cualquiera rompa los límites mínimos de la coexistencia, pone en juego el destino de la existencia humana. Me refiero a los límites mínimos del Derecho, rotos por cualquiera, los límites que tiene que tener cualquier diplomacia. E -insisto- nuestra diplomacia continental lamentablemente ha caído en una mala praxis peligrosa, que pone en peligro más de 100 años de política panamericana. Mala o buena, con sobras o con sus virtudes, pero nunca se la puso en peligro con una mala praxis diplomática como la que está sucediendo en este momento.

Realmente todo esto es lo que nos lleva a pensar que estamos tocando también un límite. Si se toca el límite de la biología cinética, si se toca el límite de la economía cinética, si cualquier tecnócrata tira la ética y maneja lo que quiere, cuidado que estamos volviendo al Estado hobbesiano, pero en ese Estado precontractual que trataba Hobbes la gente se peleaba a golpes con machetes, con palos. Cuidado porque, con la altísima tecnología y la capacidad destructiva inenarrable e ilimitada con la que contamos hoy, cada vez que se toca un límite de estos se pone en riesgo el destino futuro de la 
humanidad. Esto no es una mera cuestión de golpe de Estado, no es una mera cuestión política. Se les ha ido la mano: ahora están tocando las reglas básicas de la coexistencia entre Estados, están saliendo de la comunidad internacional.

Gracias por confiar en nosotros en este momento y quedamos a sus enteras órdenes.

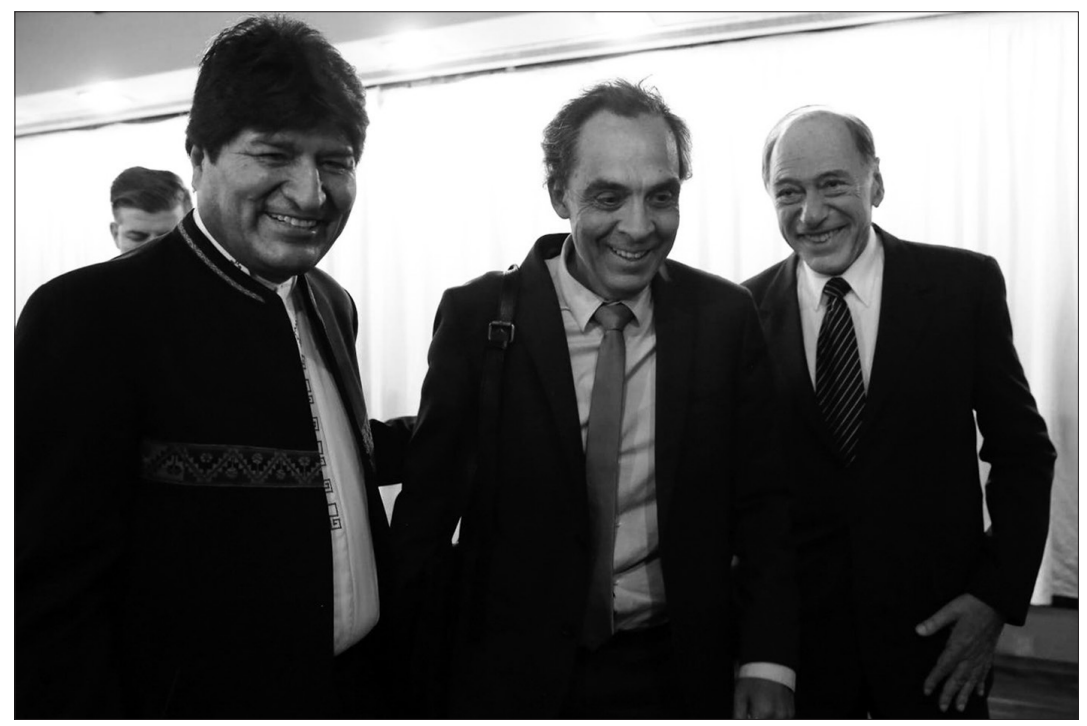

